\title{
Factors influencing choice of career: A comparative study among medical, dental and pharmacy students in a private university in Malaysia
}

Kingston Rajiah ${ }^{1}$ (D), Mari Kannan Maharajan ${ }^{1}$ (ID) , Pravinkumar Vishwanath Ingle ${ }^{1}$ (D) , Lavinyaa Thiruchelvam², Raynugah Gunasagaram², Kirthana Kanagaraj ${ }^{2}$, Tamilarasi Krishnamurthi ${ }^{2}$

${ }^{1}$ Department of Pharmacy Practice, School of Pharmacy, International Medical University, Malaysia

${ }^{2}$ School of Pharmacy, International Medical University, Malaysia

\author{
Keywords \\ Motivation \\ Career choice \\ Pharmacy \\ Cross-sectional Survey

\section{Correspondence} \\ Mari Kannan Maharajan \\ Department of Pharmacy Practice \\ School of Pharmacy \\ International Medical University \\ Kuala Lumpur 57000 \\ Malaysia \\ MariKannan@imu.edu.my
}

\begin{abstract}
Background: Students choose their careers based on many factors, which vary for every country. Recent advancements in healthcare systems have made pharmacy one of the most pursued professions. Aim: To study the factors that influence students in Malaysia to choose pharmacy as their career. Methods: A cross-sectional study was conducted among first-year medicine, dentistry and pharmacy students in a private university in Malaysia. One-way analysis of variance followed by Tukey's post-hoc test was used to determine the factors that influenced students' career choices. Results: There were significant differences among medicine, dentistry and pharmacy students in the mean scores for the dimensions 'economic status', 'personal background', and 'work-life balance' which influenced their career choice. Conclusions: Economic status, personal background and work-life balance were the factors that significantly influenced students to choose pharmacy compared with students' choice of dentistry and medicine.
\end{abstract}

\section{Introduction}

A continual growth in the global population leads to a great demand for healthcare professionals (Kehrer et al., 2013). Modern day school leavers have many different choices for pursuing a career in healthcare. The selection of the right career plays a vital role in shaping a student's future (DiPadova-Stocks, 2015). Students choose their careers based on many factors and these factors vary for each country (Kazi et al., 2017). Various studies have explored the factors influencing students to study courses in healthcare, with social status, ability to be self- employed, high professional status, helping people, and personal interest being mentioned as the reasons for their choice of profession (Bernabé et al., 2006; Gallagher et al., 2008; Hasan et al., 2010; Karibe et al., 2009; Grayson et al., 2012; Mehmood et al., 2012; Querido et al., 2015; Subait et al., 2017).
There is a general perception among the public that the medical profession has widespread popularity and respect compared to other professions (James et al., 2018). The literature has shown that 'personal fulfilment', 'salary', 'abilities to help patients', 'location of job', 'selfemployment', 'interest in science', and 'desire to be useful to society' were the factors that influenced students to choose pharmacy as their career (Bardick et al., 2006; Anderson et al., 2008; Savage et al., 2009; Keshishian et al., 2010; Abdelhadi et al., 2014; Hanna et al., 2016; Alhaddad, 2018). It was also reported that some pharmacy students' progress to healthcare professions outside of pharmacy after completing their studies, citing 'the need for more money' or 'personal reasons' (Ubaka et al., 2013). 
The expanded scope of pharmacy practice allows pharmacy graduates to start their professional lives in healthcare organisations in management, regulatory oversight, and pharmacy organisations, in addition to working in clinical and community practice (Taylor et al., 2015). Recent advancements in the field of pharmacy (Maharajan et al., 2017), the emergence of new treatments and evidence-based practice, make pharmacy an exciting and rewarding career; thus, pharmacy has become one of the most pursued professions in the healthcare field (Royal Pharmaceutical Society, 2018). Moreover, people frequently visit pharmacies and consult pharmacists for advice on health and wellbeing (Bates et al., 2016), with pharmacists being considered the most trusted professionals (Lynas, 2012).

The pharmacy profession is playing a big role in transforming the healthcare system in Malaysia (Hassali et al., 2016). The expansion of clinical pharmacy services under the Malaysian Ministry of Health, means hospitals have expanded the role of pharmacists in providing pharmaceutical care to patients (Ministry of Health Malaysia, 2020). Even though most training programmes in Malaysia are for nursing, pharmacy and medicine (World Health Organisation, 2014), transforming the healthcare system in Malaysia is demanding a larger workforce in pharmacy services. It has been reported that a considerable number of students who entered pharmacy mentioned it as a second choice, with medicine or dentistry as their first choice (Keith et al., 2006; Sholy \& Zeenny, 2013; James et al., 2018)

It is essential, therefore, to study the factors that influence students in Malaysia to choose pharmacy as their career. Although many studies have investigated the factors that influenced the career choices of medicine, dentistry and pharmacy students individually, there has been no comparative study among students of medicine, dentistry and pharmacy in Malaysia (Hasan et al., 2010; Anbuselvan et al., 2013; Kumar et al., 2014). The present study was designed to determine the factors that influenced medical, dental and pharmacy students in making their career choices in Malaysia; the findings may provide an insight for stakeholders in this matter.

\section{Methods}

\section{Participants and sample size}

A cross-sectional study was conducted in a private university in Malaysia. All first-year students undertaking undergraduate medicine, dentistry and pharmacy courses (a total of 523) were invited to participate in this study. Based on the student population at the International Medical University, the sample size was calculated using the Raosoft calculator with 95\% confidence intervals and a $5 \%$ margin of error with an expected response distribution of $50 \%$. The minimum sample size required for this study was 65 from dentistry, 153 from medicine and 128 from pharmacy - a total of 346 students.

\section{Study procedure}

The study was approved by the International Medical University Joint Committee for Research and Ethics (Ref: BP I-01/12 (43) 2015). Following approval, students were approached to participate in this study during May and October 2015. They were informed about the purpose of the study using the study information sheet and individual verbal or written consent was obtained. The students were assured that their participation was voluntary and that anonymity would be maintained. The names and identity card numbers of participants were excluded to ensure anonymity and confidentiality. Paper questionnaires were distributed to the students between weeks five and eight of their first semester. Drop boxes were kept in the lecture halls. After completing the survey, students dropped their questionnaires into these boxes. The students were asked to ensure that all the items in the questionnaire were answered. The missing data was $5 \%$ and those missing values were excluded from the analysis.

\section{Inclusion and exclusion criteria}

First-year students undertaking undergraduate medicine, dentistry and pharmacy courses were approached and those who were willing to participate in the study were included. First-year students undertaking other undergraduate courses were excluded from this study.

\section{Study questionnaire}

The questionnaire used in this study was based on previous studies (Bernabé et al., 2006; Gallagher et al., 2008; Hasan et al., 2010; Subait et al., 2017), which gave the different dimensions that affected the career choices of medical, dental and pharmacy students. The study questionnaire was in English, reflecting the language of instruction in the University, and comprised of 30 statements, which were under six dimensions. Each item contained a statement which required the respondent to indicate the level of agreement on a five-point Likert scale ranging from $0=$ Strongly Disagree to $4=$ Strongly Agree. The six dimensions were 'Economic status', 'Better 
profession', 'Service oriented', 'Interest in science/ research', 'Personal background' and 'Work-life balance'. The questionnaire was assessed for both validity and reliability. Content validity was undertaken by a panel of three subject experts and their opinion on the relevance and significance of the questionnaire was considered, with subsequent adjustments being made to the questionnaire as required. A pilot study was undertaken using 15 students to confirm the reliability of the questionnaire. The internal consistency was estimated by determining the coefficient alpha index with reference to the Cronbach's alpha value using SPSS v.20. The Cronbach's alpha values were as follows: Economic status $=0.73$; Better profession $=0.76$; Service oriented $=0.78$; Interest in science/research $=0.72$; Personal background $=0.71$; and Work-life balance $=0.72$.

\section{Data analysis}

Demographic factors were presented as frequencies and percentages. Chi-square goodness of fit test was used to analyse the proportions of medical, dental and pharmacy students who 'Strongly Agreed/Agreed' with the factors (items) which had played roles in their career decision. Means and standard deviations were calculated for the six dimensions. One-way analysis of variance (ANOVA), followed by Tukey's post-hoc test was used to find significant differences within the students' mean scores of six dimensions which had played roles in their career decision. The 'effect size' (Eta squared) test was used to examine the magnitude of the differences in the proportion of the groups (dentistry, medicine and pharmacy). An effect size value of 0.2 was considered as a 'small' effect size, 0.5 represented a 'medium' effect size and 0.8 a 'large' effect size (Sullivan \& Feinn, 2012). Homogeneity of variance was tested by using Levene's test of equality of variances. Cronbach's alpha was used to assess the internal consistency of the scales.

\section{Results}

A total of 452 students responded, comprising 203 from medicine, 182 from pharmacy and 67 from dentistry. The demographic profiles are presented in Table I. Overall, 452 out of the 523 students responded, making an overall response rate of $86.4 \%$. The response rates from different programmes were as follows: 95\% (182/191) from pharmacy; 83\% (67/80) from dentistry; 80\% (203/252) from medicine. The female:male student ratio was higher in all the programmes. All the dental students chose dentistry as their first choice of career. Among the 203 medical students, medicine was the first choice for $93.6 \%$ $(n=190)$ of the students, and dentistry was the first choice for the remaining 6.4\% $(n=13)$. Among 182 pharmacy students, pharmacy was the first choice for $87.9 \%$ $(n=160)$, medicine was the first choice for $9.9 \%(n=18)$ and dentistry was the first choice for $2.2 \%(n=04)$. The number of pharmacy students who were on education loans was high compared to medical and dental students. In this study, the family income for pharmacy students was low compared to that of medical and dental students. The range of family income for the majority of pharmacy students was low to medium, whereas that of most of the medical and dental students was medium to high. The percentage of pharmacy students on scholarships was high compared to medical and dental students.

Table I: Frequency distribution of the demographic variables of students

\begin{tabular}{lccc}
\hline Demographics & $\begin{array}{c}\text { Dentistry } \\
\mathbf{n}(\%)\end{array}$ & $\begin{array}{c}\text { Medicine } \\
\mathbf{n}(\%)\end{array}$ & $\begin{array}{l}\text { Pharmac } \\
\mathbf{n}(\%)\end{array}$ \\
\hline Gender & & & \\
Male & $22(32.9)$ & $77(37.9)$ & $70(38.5)$ \\
Female & $45(67.1)$ & $126(62.1)$ & $112(61.5)$ \\
\hline
\end{tabular}

\begin{tabular}{llll} 
First choice of specialty & & & \\
Yes & $67(100.0)$ & $190(93.5)$ & $160(87.9)$ \\
No & $00(00.0)$ & $13(06.5)$ & $22(12.1)$ \\
\hline
\end{tabular}

If no, What was your first choice

$\begin{array}{llll}\text { Not applicable } & 67(100.0) & 190(93.5) & 160(87.9) \\ \text { Dentistry } & 00(00.0) & 13(06.5) & 04(02.2) \\ \text { Medicine } & 00(00.0) & 00(00.0) & 18(09.9) \\ \text { Pharmacy } & 00(00.0) & 00(00.0) & 00(00.0)\end{array}$

On education loan

\begin{tabular}{lrrr} 
No & $55(82.1)$ & $151(74.3)$ & $64(35.1)$ \\
Yes & $12(17.9)$ & $52(25.6)$ & $118(64.8)$ \\
\hline
\end{tabular}

On scholarship

\begin{tabular}{lrrr} 
No & $59(88.1)$ & $168(82.8)$ & $137(75.3)$ \\
Yes & $08(11.9)$ & $35(17.2)$ & $45(24.7)$ \\
\hline
\end{tabular}

Family income per month

$\begin{array}{llrl}\text { Low }\left(<8,000 \mathrm{RM}^{*}\right) & 00(00.0) & 00(00.0) & 42(23.2) \\ \text { Medium }\left(8,000-15,000 \mathrm{RM}^{*}\right) & 18(26.9) & 76(37.3) & 76(41.7) \\ \text { High }\left(>15,000 \mathrm{RM}^{*}\right) & 49(73.1) & 127(62.7) & 64(35.1)\end{array}$

${ }^{*}$ RM- Ringgit Malaysia 
Table II: Comparison of the proportion of students agreeing on the factors to choose their career

\begin{tabular}{|c|c|c|c|c|}
\hline Dimensions & $\begin{array}{l}\text { Dentistry } \\
\text { n (\%) }\end{array}$ & $\begin{array}{l}\text { Medicine } \\
\text { n (\%) }\end{array}$ & $\begin{array}{c}\text { Pharmacy } \\
\text { n (\%) }\end{array}$ & $p$-value \\
\hline \multicolumn{5}{|l|}{ Economic status } \\
\hline Better salary & $57(85)$ & $180(88)$ & $150(82)$ & 0.142 \\
\hline $\begin{array}{l}\text { Financially } \\
\text { independent }\end{array}$ & $59(89)$ & 182(89) & $122(67)$ & $0.031^{*}$ \\
\hline Easy employment & $55(82)$ & $164(80)$ & $140(76)$ & 0.236 \\
\hline Make more money & $52(77)$ & 170(83) & $144(79)$ & 0.473 \\
\hline Prestige & $50(74)$ & $172(84)$ & $150(82)$ & 0.158 \\
\hline \multicolumn{5}{|l|}{ Better profession } \\
\hline Job security & $57(85)$ & $135(66)$ & $122(67)$ & $0.048^{*}$ \\
\hline $\begin{array}{l}\text { Better work } \\
\text { environment }\end{array}$ & $52(77)$ & $160(78)$ & $138(75)$ & 0.285 \\
\hline Exciting job & $50(74)$ & $162(79)$ & $133(73)$ & 0.348 \\
\hline Self-employment & $53(79)$ & $148(72)$ & $122(67)$ & $0.022^{*}$ \\
\hline No hectic work & $56(83)$ & $168(82)$ & $148(81)$ & 0.316 \\
\hline \multicolumn{5}{|l|}{ Service oriented } \\
\hline Treat/help people & $50(74)$ & $160(78)$ & $140(76)$ & 0.242 \\
\hline Interact with people & $52(77)$ & $154(75)$ & $148(81)$ & 0.187 \\
\hline Help those in need & $49(73)$ & $148(72)$ & $144(79)$ & 0.263 \\
\hline Help sick people & $51(76)$ & $151(74)$ & $140(76)$ & 0.418 \\
\hline Help the society & $53(79)$ & $165(81)$ & $150(82)$ & 0.282 \\
\hline \multicolumn{5}{|c|}{ Interest in science/research } \\
\hline Perform research & $44(65)$ & $122(60)$ & $122(67)$ & 0.167 \\
\hline Work scientifically & $48(71)$ & $135(66)$ & 144(79) & 0.343 \\
\hline Innovation & $42(62)$ & $160(78)$ & $140(76)$ & 0.296 \\
\hline Research grants & $45(67)$ & $134(66)$ & $122(67)$ & 0.422 \\
\hline $\begin{array}{l}\text { Become a research } \\
\text { scientist }\end{array}$ & $40(59)$ & $112(55)$ & $108(59)$ & 0.368 \\
\hline \multicolumn{5}{|l|}{ Personal background } \\
\hline Family encouraged & $61(91)$ & 192(94) & $128(70)$ & $0.021^{*}$ \\
\hline Friends encouraged & $52(77)$ & $154(75)$ & $122(67)$ & 0.323 \\
\hline $\begin{array}{l}\text { Role model's } \\
\text { profession }\end{array}$ & $55(82)$ & $140(68)$ & $133(73)$ & 0.295 \\
\hline $\begin{array}{l}\text { Read/heard a lot on } \\
\text { this profession }\end{array}$ & $51(76)$ & $158(77)$ & $140(76)$ & 0.182 \\
\hline $\begin{array}{l}\text { Only few years of } \\
\text { education }\end{array}$ & $55(82)$ & $130(64)$ & $150(82)$ & $0.042^{*}$ \\
\hline \multicolumn{5}{|l|}{ Work-life balance } \\
\hline Full time or part time & 61(91) & $179(88)$ & $160(87)$ & 0.124 \\
\hline Time with my family & $32(52)$ & $108(53)$ & $150(82)$ & $0.013^{*}$ \\
\hline Work as a locum & $55(82)$ & $177(87)$ & $138(75)$ & 0.235 \\
\hline Go on vacation & $30(51)$ & $105(51)$ & $148(81)$ & $0.012^{*}$ \\
\hline Work abroad & $50(74)$ & $154(75)$ & $122(67)$ & 0.286 \\
\hline
\end{tabular}

*Statistically significant at 0.05 level
The influential factors are presented in Table II. About $89 \%(n=60)$ of dental students were influenced by the factor 'Financially independent' which was significantly higher than the pharmacy students $(p=0.03)$. Other factors such as; 'Easy employment', 'Intention to make money' and 'Prestige' did not show any significant variation among the students. About $85 \%(n=57)$ of dental students choose this career for perceived job security; this proportion was significantly higher than that of medical and pharmacy students $(p=0.05)$. About $79 \%(n=53)$ of dental students were influenced by the self-employment opportunities, which was significantly higher than pharmacy students $(p=0.02)$. Other factors such as work environment, excitement in the job and hectic work life did not show any significant variation among the students. Factors relating to service of people and society also showed no significant variation; however, the proportions of students agreeing with these factors were equally high among all the students. The factors relating to Interest in science/research showed no significant variation among the students. About $94 \%$ ( $n=192)$ of medical students and $91 \%(n=61)$ of dental students were influenced by their family members, which was significantly higher than the pharmacy students $(p=0.02)$. About $82 \% \quad(n=150)$ of pharmacy students were influenced by the years (duration) they have to spend in education, which was significantly higher than the medical and dental students $(p=0.04)$. Work-life balance was another factor influencing pharmacy students significantly $(p=0.01)$ more than medical and dental students; about $82 \%(n=150)$ of pharmacy students were influenced to enter this profession so that they can spend time with their family and take a vacation when needed.

The differences among students on the six dimensions are presented in Table III. There was a significant difference among the students for the dimension 'Economic status'. Medical students scored higher than the dental and pharmacy students $(F(3,452)=11.82, p=0.04)$. The effect size was 0.48 , revealing that the size of the difference was small. There were no significant differences among the students for the dimensions 'Better profession' $(F(3,452)$ $=12.58, p=0.13)$, 'Service oriented' $(F(3,452)=11.45, p=0.15)$, or 'Interest in science/research' ( $F(3,452)=12.82, p=0.13)$. There was a significant difference among the students in the dimension 'Personal background'. Medical students scored higher than the dental and pharmacy students $(F$ $(3,452)=13.25, p=0.05)$. The effect size was 0.56 which revealed that the size of the difference was medium. There was also a significant difference among the students for the dimension 'Work-life balance'. Pharmacy students scored higher than the dental and medical students $(F$ $(3,452)=13.25, p=0.05)$. The effect size was 0.81 which revealed that the size of the difference was large. 
Table III: Comparison of students' mean scores on six dimensions

\begin{tabular}{|c|c|c|c|c|}
\hline Dimensions & Students & Mean scores & F ratio, significance & Partial Eta squared \\
\hline \multirow[t]{3}{*}{ Economic status } & Dentistry & 18.23 & $\mathrm{~F}(3,452)=11.82, p=0.041^{*}$ & \\
\hline & Medicine & 19.46 & & Med vs Pharm $=0.481$ \\
\hline & Pharmacy & 15.63 & & \\
\hline \multirow[t]{3}{*}{ Better profession } & Dentistry & 18.45 & $F(3,452)=12.58, p=0.134$ & \\
\hline & Medicine & 19.21 & & NA \\
\hline & Pharmacy & 16.98 & & \\
\hline \multirow[t]{3}{*}{ Service oriented } & Dentistry & 14.45 & $F(3,452)=11.45, p=0.152$ & \\
\hline & Medicine & 15.26 & & NA \\
\hline & Pharmacy & 16.15 & & \\
\hline \multirow[t]{3}{*}{ Interest in science/research } & Dentistry & 12.24 & $\mathrm{~F}(3,452)=12.82, p=0.136$ & \\
\hline & Medicine & 11.82 & & NA \\
\hline & Pharmacy & 15.43 & & \\
\hline \multirow[t]{3}{*}{ Personal background } & Dentistry & 18.22 & $\mathrm{~F}(3,452)=13.25, p=0.049^{*}$ & \\
\hline & Medicine & 19.48 & & Med vs Pharm $=0.564$ \\
\hline & Pharmacy & 15.56 & & \\
\hline \multirow[t]{3}{*}{ Work-life balance } & Dentistry & 18.36 & $\mathrm{~F}(3,452)=13.37, p=0.012^{*}$ & \\
\hline & Medicine & 19.63 & & Pharm vs Med $=0.812$ \\
\hline & Pharmacy & 14.24 & & \\
\hline
\end{tabular}

${ }^{*}$ Statistically significant at 0.05 level

\section{Discussion}

This study was conducted among first year medical, dental and pharmacy students at a private university in Malaysia in 2015 to determine the factors which led them to choose their careers. The higher proportion of female participants reflected the higher female:male student ratio in all the healthcare universities in Malaysia (Hasan et al., 2010). This result reflects the tendency for females to be significantly more interested in the healthcare profession than males (Gretchen et al., 2019).

For all the participants from dental programmes, dentistry was their first choice to study. Previous studies in various countries showed that 'Self-employment', 'Financial independence' (Kapoor et al., 2014) and 'Job security' (Brand et al., 1996) were significant factors influencing the career choice of dental students. Crossley and Mubarik (2002) reported that dental students chose dentistry because of 'Regular working hours', 'Self-employment' and 'Independence'. Students in Malaysia choose dentistry for various reasons, including a desire to achieve financial stability and work-life balance (Che Musa et al., 2016). In the present study, 'Job security' and 'Selfemployment' appeared to be important factors influencing career choice among dental students.
A high percentage of medical students identified medicine as their first choice. In this study, economic status and personal background are the reasons for students to choose medicine. Usually students choose medicine for various reasons such as global recognition, job opportunities abroad, status and respect in society, stability in employment, and job security (Newton et al., 1998; Woodward et al., 2017).

Although lower than dental (100\%) and medical (93.5\%) students, pharmacy was the first choice $(87.9 \%)$ among pharmacy students. The diversity of the pharmacy profession, and the various opportunities in healthcare within Malaysia encourages students to choose pharmacy as a career (Hasan et al., 2010; Loo et al., 2017). With a two-tier healthcare system consisting of the public and private sectors, and given the growing demand for healthcare services, pharmacists need to take more responsibilities within the healthcare system (Kehrer et al., 2013; Christopher, 2018).

In this study, most of the pharmacy students were in receipt of education loans due to their relatively low family incomes. This is a global issue, as graduates are seeking financial stability, particularly after an extensive 
education that has left them with significant amounts of debt (Cain et al., 2014). Hence, countries such as United States, Canada, United Kingdom and Australia have a 'Student Loan Forgiveness Programme' to relieve them from debt (Federal Student Aid, 2013; Government Digital Service, 2014; Karnezis, 2018; Government of Canada, 2019). The results of the study reflected that a higher proportion of pharmacy students are in receipt of scholarships than that of medical or dental students. Meanwhile, the Malaysian Public Service Department, has announced that all government scholarships from 2016 will be in the form of convertible loans (Balakrishnan, 2016). This means that upon completion of studies, all scholars, who received a scholarship from the Public Service Department are mandated to work in the public sector. If graduates choose to work in government-linked companies (GLCs) or in the private sector, they must pay back $25 \%$ or $50 \%$ of the scholarship amount respectively (Malaysiakini, 2016).

Unlike dental students, pharmacy students were not influenced by the factors 'Financially independent', 'Job security', or 'Self-employment opportunity'. This may be due to the fact that most pharmacists in Malaysia prefer to work in community pharmacies (Siracuse et al., 2004; Carvajal \& Armayor, 2013). Also, pharmacists in community pharmacies have job security and are fully financially independent if they own a pharmacy and are self-employed (Hirschi \& Vondracek, 2009: Savage et al., 2009).

'Service to people and society' was a key factor among all the medical, dental and pharmacy students, with no significant differences among the three groups; this shows that all three groups of health professional students are focused on serving the public and improving healthcare in society. The results are an indication of students preparedness to be part of a public health workforce. According to Frenk and colleagues (2010) preparing health professionals to be part of the public health workforce of the future is a key element of the quality of education.

There were no significant differences among the three student groups on the importance of 'Interest in science/research' as a factor influencing the choice of career. However, Saunders and Fogarty (2001) reported that career preferences may change over time so that research, as a career opportunity, may attract students in the later years of their course or after graduation. In this study, students did not show interest in research at this point and it may change in the future as the bachelor's degree programmes have a research components in the later semesters.
Pharmacy students were less influenced by their families than medical students for their career choices. This may suggest that pharmacy students' family members might not have a pharmacy background or they do not show a high preference for pharmacy as a career choice. Inequalities in wages and salaries globally (Rao \& Indla, 2010; Hanna et al., 2016) and in Malaysia (Hasan et al., 2010; Manan et al., 2015; ) for pharmacists may have discouraged families/parents from preferring pharmacy over medicine and dentistry.

The results of this study also revealed that the duration of the course was one of the factors influencing students' career choice. The pharmacy courses in Malaysia are for four years, whereas both medical and dental courses are five years in duration; thus the one-year difference in course length may have influenced the students' career choices. Earlier studies also found that spending a number of years in the pursuit of a degree delays students' gains attained through a job and income (Rao \& Indla, 2010; Pheng et al., 2018), with students wanting to start earning as soon as possible. While shorter courses do, however, provide more immediate rewards, these tend to be less substantial in the long term (Rao \& Indla, 2010; Pheng et al., 2018).

'Economic status' and 'Personal background' influence the career choices of both medical and pharmacy students (Lefevre et al., 2010; Alhomoud et al., 2019). Research has shown that people tend to adjust their behaviour and decision-making in an adaptive way, according to environmental circumstances, and decide on career choices that involve lower investment (Hill et al., 2008; Gigerenzer \& Goldstein, 2011).

Work-life balance improves long-term productivity in any profession, as indicated by previous studies (Rao \& Indla, 2010; Pheng et al., 2018). The present study also shows that work-life balance influenced the career choices of the students. Pharmacy students would like to spend more time with their families and be able to take a vacation; these were significantly greater influences for pharmacy students than for medical students. However, choosing one field over the other depends on individual interests, abilities, desired work environment and the lifestyle the individual wants to lead (Omar, 2016).

\section{Strengths and limitations}

This study revealed the factors that influenced first year undergraduate students to choose pharmacy over medicine and dentistry as their career at one private 
Malaysian university and provides a better picture of student preference for pharmacy compared with the other programmes in this setting.

The findings are limited to the pharmacy students in one private Malaysian university and cannot be extrapolated to a wider population of pharmacy students in Malaysia. The generalisability of the findings should be evaluated in future studies.

\section{Conclusions}

Economic status, personal background and work-life balance were the main factors that influenced first-year students to choose pharmacy over the other two professions. Pharmacy students were not influenced differently from medical and dental students by other factors, such as profession, service to society and research. Further research is needed to study students' experience in their professional practice and subsequent achievement in their career.

\section{Acknowledgments}

This research was supported by the Institute for Research, Development \& Innovation, International Medical University, Malaysia. All the authors acknowledge Professor Brian L. Furman, Emeritus Professor of Pharmacology, Strathclyde Institute of Pharmacy \& Biomedical Sciences, Glasgow for his valuable comments on an earlier version of the manuscript and his help in improving the use of English in the manuscript.

\section{References}

Abdelhadi, N., Wazaify, M., Elhajji, F., \& Basheti, I. (2014). Doctor of Pharmacy in Jordan: Students career choices, perceptions and expectations. Journal of Pharmacy and Nutrition Sciences, 4(3), 213-219. https://doi.org/10.6000/1927-5951.2014.04.03.7

Alhaddad, M.S. (2018). Undergraduate pharmacy students motivations, satisfaction levels, and future career plans. Journal of Taibah University Medical Sciences, 13(3), 247-253. https://doi.org/10.1016/i.jtumed.2018.03.004

Alhomoud, F. K., Alghalawin, L., Algofari, G., Aldjani, W., Ameer, A., \& Alhomoud, F. (2019). Career choices and preferences of Saudi pharmacy undergraduates: a cross sectional study. Saudi Pharmaceutical Journal, 27(4), 467-474 . https://doi.org/10. 1016/i.jsps.2019.01.009
Anbuselvan, G.P., Gokulnathan, S., Praburajan, V., Rajaraman, G., Kumar, S.S., \& Thagavelu, A. (2013). A study among dental students regarding the factors influenced dental students to choose dentistry as career. Journal of Pharmacy and Bioallied Sciences, 5(1), S36-S38. https://doi.org/10.4103/0975-7406.113292

Anderson, D.C., Sheffield, M.C., Hill, A.M., \& Cobb, H.H. (2008). Influences on pharmacy students decision to pursue a Doctor of Pharmacy Degree. American Journal of Pharmaceutical Education, 72(2), 22. https://doi.org/10.5688/aj720222

Balakrishnan., N. (2016). You now have to pay back your jpa scholarships if you don't want to work in civil service. SAYS (online). Available at: https://says.com/my/news/ipa-scholarshipsconverted-into-loans-starting-2016

Bardick, A.D., Bernes, K.B., Magnusson, K.C., \& Witko, K.D. (2006). Junior high school students career plans for the future. Journal of Career Development, 32(3), 250-271. https://doi.org/10.1177/ $\underline{0894845305279168}$

Bates, I., John, C., Bruno, A., Fu, P., \& Aliabadi, S. (2016). An analysis of the global pharmacy workforce capacity. Human Resources for Health, 14(61). https://doi.org/10.1186/s12960-016-0158-z

Bernabé, E., Icaza, J.L., \& Delgado-Angulo, E.K. (2006). Reasons for choosing dentistry as a career: A study involving male and female first-year students in Peru. European Journal of Dental Education, 10(4), 236-241. https://doi.org/10.1111/i.1600-0579.2006.00422.x

Brand, A.A., Chikte, U.M., \& Thomas, C.J. (1996). Choosing dentistry as a career - a profile of entering students (1992) to the University of Sydney, Australia. Australian Dental Journal, 41(3), 198-205. https://doi.org/10.1111/i.1834-7819.1996.tb04856.x

Cain, J., Campbell, T., Congdon, H.B., Hancock, K., Kaun, M., Lockman, P.R., \& Evans, R.L. (2014). Complex issues affecting student pharmacist debt. American Journal of Pharmaceutical Education, 78(7), 131. https://doi.org/10.5688/ajpe787131

Carvajal, M.J., \& Armayor, G.M. (2013). Inequalities in the distribution of pharmacists wage-and-salary earnings: Indicators and their development. Research in Social and Administrative Pharmacy, 9(6), 930-948. https://doi.org/10.1016/j.sapharm. $\underline{2013.01 .004}$

Che Musa M.F., Bernabé, E., \& Gallagher, J.E. (2016). Career expectations and influences among dental students in Malaysia. International Dental Journal, 66(4), 229-36. https://doi.org/10.1111/idj.12224

Christopher, J. (2018) The changing role of the pharmacist in the 21st century. The Pharmaceutical Journal, 300(7909). https://doi. org/10.1211/PJ.2018.20204131

Crossley, M.L., \& Mubarik, A. (2002). A comparative investigation of dental and medical students motivation towards career choice. British Dental Journal, 193(8), 471-473. https://doi.org/10.1038/sj. $\underline{\text { bdj.4801599 }}$

DiPadova-Stocks, L.N. (2015). Higher Education Shaping the Unscripted Future: The Imperative to Affirm Human Values in Transformative Times. In A. Dailey-Hebert \& K. Dennis (Eds.), Transformative Perspectives and Processes in Higher Education. Advances in Business Education and Training. Springer, Cham. https://doi.org/10.1007/978-3-319-09247-8 12 
Federal Student Aid. (2013). The US Department of Education. Federal student aid: public service loan forgiveness (online). Available at: http://studentaid.ed.gov/repay-loans/forgiveness -cancellation/charts/public-service.

Frenk, J., Chen, L., Bhutta, Z.A., Cohen, J., Crisp, N., Evans, T. Fineberg, H., Garcia, P., Ke, Y., Kelley, P., Kistnasamy, B., Meleis, A., Naylor, D., Pablos-Mendez, A., Reddy, S., Scrimshaw, S. Sepulveda, J., Serwadda, D., \& Zurayk, H. (2010). Health professionals for a new century: transforming education to strengthen health systems in an interdependent world. The Lancet, 376, 1923-1958. https://doi.org/10.1016/S0140-6736(10) $\underline{61854-5}$

Gallagher, J., Clarke, W., \& Wilson, N. (2008). Understanding the motivation: A qualitative study of dental students choice of professional career. British Dental Journal, 205(9), 493-493. https://doi.org/10.1038/sj.bdj.2008.947

Gigerenzer, G., \& Goldstein, D.G. (2011). Reasoning the fast and frugal way: Models of bounded rationality. Heuristics, 33-55. https://doi.org/10.1093/acprof:oso/9780199744282.003.0002

Government Digital Service. (2014). Repaying your student loan (online). Available at: https://www.gov.uk/repaying-your-student -loan/which-repayment-plan-you-are-on

Government of Canada. (2019). Social Development Canada (online). Available at: https://www.canada.ca/en/services/ benefits/education/student-aid/grants-loans/repay/assistance/do ctors-nurses/amount.html

Grayson, M.S., Newton, D.A., \& Thompson, L.F. (2012). Payback time: The associations of debt and income with medical student career choice. Medical Education, 46(10), 983-991. https://doi.org/10.1111/i.1365-2923.2012.04340.x

Gretchen, B., Lucia, D., Megan, G., \& Irina, S. (2019). Women in the healthcare industry (online). Available at: https://www.mckinsey. com/industries/healthcare-systems-and-services/our-insights/wo men-in-the-healthcare-industry\#

Hanna, L.A., Askin, F., \& Hall, M. (2016). First-Year Pharmacy Students' Views on their chosen professional career. American Journal of Pharmaceutical Education, 80(9), 150. https://doi.org/ $\underline{10.5688 / a j p e 809150}$

Hasan, S.S., Kwai Chong, D.W., Ahmadi, K., Se, W.P., Hassali, M.A., Hata, E.M., Hadi, M.A., Sridhar, S.B., Ahmed, S.I., Yean, L.B., \& Efendie, B. (2010). Influences on Malaysian pharmacy students' career preferences. American Journal of Pharmaceutical Education, 74(9), 166. https://doi.org/10.5688/aj7409166

Hassali, M.A., Shafie, A.A., Ooi, G.S., \& Wong, Z.Y. (2016). Pharmacy Practice in Malaysia. In A.I. Fathelrahman, M.I.M Ibrahim \& A.I. Wertheimer (Eds.), Pharmacy practice in developing countries: Achievements and challenges. United Kingdom: Elservier

Hill, E.M., Jenkins, J., \& Farmer, L. (2008). Family unpredictability, future discounting and risk taking. The Journal of Socio-Economics, 37(4), 1381-1396. https://doi.org/10.1016/j.socec.2006.12.081

Hirschi, A., \& Vondracek, F.W. (2009). Adaptation of career goals to self and opportunities in early adolescence. Journal of Vocational Behavior, 75(2), 120-128. https://doi.org/10.1016/ j.jvb.2009.05.005
James, P.B., Batema, M.N., Bah, A.J., Brewah, T.S., Kella, A.T., Lahai, M., \& Jamshed, S.Q. (2018). Was pharmacy their preferred choice? Assessing pharmacy students' motivation to study pharmacy, attitudes and future career intentions in Sierra Leone. Health Professions Education, 4(2), 139-148. https://doi.org/ 10.1016/i.hpe.2017.06.001

Kapoor, S., Puranik, M., \& Uma, S. (2014). Factors influencing dental professional career in India: An exploratory survey. Journal of Indian Association of Public Health Dentistry, 12(2), 113. https://doi.org/10.4103/2319-5932.140278

Karibe, H., Kawakami, T., Suzuki, A., Warita, S., Ogata, K., Aoyagi, K., \& Dahllöf, G. (2009). Career choice and attitudes towards dental education amongst dental students in Japan and Sweden. European Journal of Dental Education, 13(2), 80-86. https://doi.org/10.1111/i.1600-0579.2008.00543.x

Karnezis, J. (2018). Pharmacists Student Loan Forgiveness Guide. Credible (online). Available at: https://www.credible.com/blog/ refinance-student-loans/pharmacists-student-loan-forgiveness-gu ide/

Kazi, A.A., Nimra, S., \& Nawaz, A. (2017). Factors influencing students' career choices: empirical evidence from business students. Journal of Southeast Asian Research, $\mathbf{7 1 8 8 4 9 .}$ https://doi.org/10.5171/2017.718849

Kehrer, J. P., Eberhart, G., Wing, M., \& Horon, K. (2013). Pharmacy's role in a modern health continuum. Canadian Pharmacists Journal / Revue Des Pharmaciens Du Canada, 146(6) 321-324. https://doi.org/10.1177/1715163513506370

Keith, W., Jill, J., Chris, L., Katie, H., \& Laura, C. (2006). Pharmacy undergraduate students: career choices \& expectations across a four-year degree programme (online). Available: https://pharm acyresearchuk.org/wp-content/uploads/2012/11/Pharmacy und ergraduate students career choices and expectations.pdf.

Keshishian, F., Brocavich, J.M., Boone, R.T., \& Pal, S. (2010). Motivating factors influencing college students choice of academic major. American Journal of Pharmaceutical Education, 74(3), 46. https://doi.org/10.5688/aj740346

Kumar, A., Mitra, K., Nagarajan, S., \& Poudel, B. (2014). Factors influencing medical students' choice of future specialization in medical sciences: a cross-sectional questionnaire survey from medical schools in China, Malaysia and regions of South asian association for regional cooperation. North American Journal of Medical Sciences, 6(3), 119-125. https://doi.org/10.4103/1947$\underline{2714.128473}$

Lefevre, J.H., Roupret, M., Kerneis, S., \& Karila, L. (2010). Career choices of medical students: A national survey of 1780 students. Medical Education, 44(6), 603-612. https://doi.org/10.1111/ i.1365-2923.2010.03707.x

Loo, J.S., Lim, S.W., Ng, Y.K., \& Tiong, J.J. (2017). Pharmacy students in private institutions of higher education: motivating factors when studying pharmacy and influences on university choice. International Journal of Pharmacy Practice, 25(6), 429-437. https://doi.org/10.1111/ijpp.12352

Lynas, K. (2012). Professionals you can trust: Pharmacists top the list again in Ipsos Reid Survey. Canadian Pharmacists Journal / Revue Des Pharmaciens Du Canada, 145(2), 55-55. https://doi.org/10.3821/145.2.cpi55c 
Maharajan, M.K., Rajiah, K., Tam, A.M., Chaw, S.L., Ang, M.J., \& Yong, M.W. (2017). Pharmacy students' anxiety towards research during their undergraduate degree; How to reduce it? PLOS ONE,12(4), e0176095. https://doi.org/10.1371/journal.pone.0176095

Malaysiakini. (2016). Review JPA's 'convertible loan' scholarship policy, gov't told (online). Available at: https://www.malay siakini.com/letters/331929

Manan, M.M., Azmi, Y., Lim, Z., Neoh, C.F., Khan, T.M., \& Ming, L.C. (2015). Predictors of job satisfaction amongst pharmacists in Malaysian public hospitals and healthcare clinics. Journal of Pharmacy Practice and Research, 45(4), 404-411. https://doi.org/10.1002/ippr.1094

Mehmood, S.I., Kumar, A., Al-Binali, A., \& Borleffs, J.C. (2012). Specialty preferences: Trends and perceptions among Saudi undergraduate medical students. Medical Teacher, 34(Sup.1), 551-560. https://doi.org/10.3109/0142159X.2012.656753

Ministry of Health Malaysia. (2020). Pharmacy Programme Strategic Plan 2017 - 2020. Pharmaceutical Services Programme. (online). Available at: https://www.pharmacy.gov.my/v2/ en/documents/pharmacy-programme-strategic-plan-2017-2020.htm

Newton, D.A., Grayson, M.S., \& Whitley, T.W. (1998). What predicts medical student career choice? Journal of General Internal Medicine, 13(3), 200-203. https://doi.org/10.1046/i.15251497.1998.00057.x

Omar, M.K.B. (2016). Work-Life Balance and Job Satisfaction among Malaysian Healthcare Employees. Environment-Behaviour Proceedings Journal, 1(4), 271. https://doi.org/10.21834/e-bpi.v1i4.177

Pheng, L.S., \& Chua, B.K. (2018). Work-Life Balance and Work-Life Interface. Work-Life Balance in Construction Management in the Built Environment, 7-17. https://doi.org/10.1007/978-981-13-191 8-12

Querido, S.J., Vergouw, D., Wigersma, L., Batenburg, R.S., Rond, M.E., \& Cate, O.T. (2015). Dynamics of career choice among students in undergraduate medical courses. A BEME systematic review: BEME Guide No. 33. Medical Teacher, 38(1), 18-29. https://doi.org/10.3109/0142159X.2015.1074990

Rao, T.S., \& Indla, V. (2010). Work, family or personal life: Why not all three? Indian Journal of Psychiatry, 52(4), 295. https://doi.org/10.4103/0019-5545.74301

Royal Pharmaceutical Society. (2018). Pharmacy careers. How do I become a pharmacist? (online). Available at: https://www. rpharms.com/resources/careers-information

Saunders, B., \& Fogarty, G. (2001). Time Discounting in Relation to Career Preferences. Journal of Vocational Behavior, 58(1), 118-126. https://doi.org/10.1006/jvbe.2000.1758

Savage, L.M., Beall, J.W., \& Woolley, T.W. (2009). Factors That Influence the Career Goals of Pharmacy Students. American Journal of Pharmaceutical Education, 73(2), 28. https://doi.org/10.5688/aj730228

Sholy, L., \& Zeenny, R. (2013). A Career Exploration Assignment for First-Year Pharmacy Students. American Journal of Pharmaceutical Education, 77(9), 195. https://doi.org/10.5688/ajpe779195

Siracuse, M.V., Schondelmeyer, S.W., Hadsall, R.S., \& Schommer, J.C. (2004). Assessing career aspirations of pharmacy students. American Journal of Pharmaceutical Education, 68(3), 75. https://doi.org/10.5688/aj680375
Subait, A.A., Ali, A., Andijani, A.I., Altuwaijry, M.A., Algarni, S.M., Alduhaimi, T.S., Metwally, A.E. (2017). Factors influencing the career choices among medical university students of King Saub bin Abdulaziz University, Riyadh Saudi Arabia; A Cross-sectional Study Design. The Saudi Journal for Dental Research, 8(1-2), 73-78. https://doi.org/10.1016/j.sjdr.2016.05.003

Sullivan, G.M., \& Feinn, R. (2012). Using effect size - or Why the P value is not enough? Journal of Graduate Medical Education, 4(3), 279-282. https://doi.org/10.4300/JGME-D-12-00156.1

Taylor, C.T., Adams, A.J., Albert, E.L., Cardello, E.A., Clifford, K., Currie, J.D., Gonyeau, M., Nelson, S.P., \& Bradley-Baker, L.R. (2015). Report of the 2014-2015 Professional Affairs Standing Committee: Producing Practice-Ready Pharmacy Graduates in an Era of Value-Based Health Care. American Journal of Pharmaceutical Education, 79(8), S12. https://doi.org/10.5688/ ajpe798S12

Ubaka, C.M., Ochie, U.M., \& Adibe, M.O. (2013). Student pharmacists' career choices: A survey of three Nigerian schools of pharmacy. Pharmacy Practice, 11(3), 149-155. https://doi.org/ $\underline{10.4321 / \mathrm{S} 1886-36552013000300005}$

Woodward, A., Thomas, S., Jalloh, M. B., Rees, J., \& Leather, A. (2017). Reasons to pursue a career in medicine: A qualitative study in Sierra Leone. Global Health Research and Policy, 2(1). https://doi.org/10.1186/s41256-017-0054-7

World Health Organisation. (2014). Human resources for health country profiles: Malaysia (online). Available at: https://iris.wpro.who.int/handle/10665.1/10530 